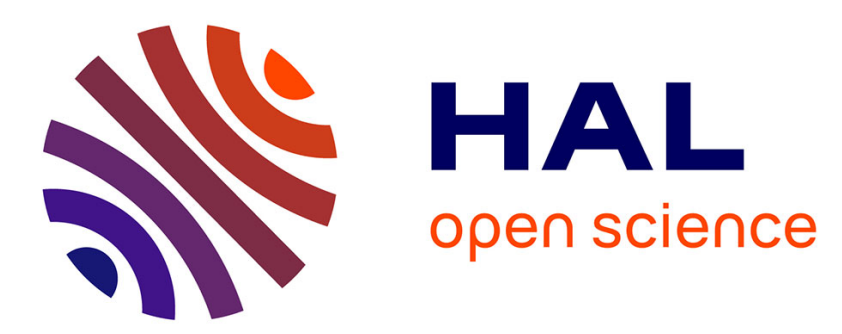

\title{
Electronic band structure and Raman property of mixed MX chain : PtIxCl1-x
}

\author{
X. Huang, Adrian N. Bishop, G. Gammel
}

\section{To cite this version:}

X. Huang, Adrian N. Bishop, G. Gammel. Electronic band structure and Raman property of mixed MX chain: PtIxCl1-x. Journal de Physique IV Proceedings, 1993, 03 (C2), pp.C2-145-C2-149. 10.1051/jp4:1993229 . jpa-00251312

\section{HAL Id: jpa-00251312 https://hal.science/jpa-00251312}

Submitted on 1 Jan 1993

HAL is a multi-disciplinary open access archive for the deposit and dissemination of scientific research documents, whether they are published or not. The documents may come from teaching and research institutions in France or abroad, or from public or private research centers.
L'archive ouverte pluridisciplinaire HAL, est destinée au dépôt et à la diffusion de documents scientifiques de niveau recherche, publiés ou non, émanant des établissements d'enseignement et de recherche français ou étrangers, des laboratoires publics ou privés. 


\title{
Electronic band structure and Raman property of mixed MX chain: $\operatorname{PtI}_{x} \mathrm{Cl}_{1_{-x}}$
}

\author{
X.Z. HUANG, A.R. BISHOP and G.T. GAMMEL
}

\section{T-11, MS-B262, Los Alamos National Labs., Los Alamos, NM 87545, U.S.A.}

We investigated theoretically the electronic and optical properties of the mixed halogenbridged-mixed-valence-transition-metal (MX) linear chain compounds $\mathrm{PtI}_{x} \mathrm{Cl}_{1-x}$. Similar to our earlier results for $\mathrm{PtBr}_{x} \mathrm{Cl}_{1-x}[1], \mathrm{PtI}_{x} \mathrm{Cl}_{1-x}$ exhibits a segment length dependence of optical Raman spectra, but shows a different quantitative behavior. The competition between the PtI segment length and its characteristic coherence length, coupled with electron-lattice coupling results in the initial increase and then decrease of PtI Raman segment frequency as a function of its segment length. The PtI segment Raman modes and their accompanying $\mathrm{PtCl}$ modes have good agreement with the experimental data. A possible novel charge separation effect associated with photoexcitation (e.g. exciton) is discussed.

We have previously reported our study on the segment length dependence of optical Raman spectra in the mixed halogen-bridged-mixed-valence-transition-metal (MX) linear chain compound (hereafter referred as mixed halide) $\left[\mathrm{Pt}^{I I}(\mathrm{en})_{2}\right]\left[\mathrm{Pt}^{I V} \mathrm{X}_{2}(\mathrm{en})_{2}\right] \mathrm{ClO}_{4}(\mathrm{X}=\mathrm{Cl}$ or $\mathrm{Br}$ ), abbreviated as $\mathrm{PtBr}_{x} \mathrm{Cl}_{1-x}$ [1]. $\mathrm{Pt}^{I I}$ (reduced) and $\mathrm{Pt}^{I V}$ (oxidized) denote two types of $\mathrm{Pt}$ valences. We were able to quantitatively associate the experimentally observed Raman frequencies with different $\mathrm{PtBr}$ segment lengths embedded in a $\mathrm{PtCl}$ environment. We found that the $\mathrm{PtBr}$ Raman frequency decreases monotonically as its segment length increases, and that there is a photo-excited charge separation effect as a result of hybridized energy levels [2].

In this paper, we study the mixed halide $\mathrm{PtI}_{x} \mathrm{Cl}_{1-x}$. Compared to $\mathrm{PtBr}_{x} \mathrm{Cl}_{1-x}$, where both $\mathrm{PtCl}$ and $\mathrm{PtBr}$ are relatively localized charge-density-waves (CDWs), $\mathrm{PtI}_{x} \mathrm{Cl}_{1-x}$ is a mixture of a strong $(\mathrm{PtCl})$ and a weak (PtI) CDW materials. PtI is a delocalized CDW reflected by its small Peierls energy gap $(1 \mathrm{eV})$ and long polaronic defect width (typically 30 sites) [3]. The big difference between CDW strengths of $\mathrm{PtBr}$ and $\mathrm{PtI}$ distinguishes $\mathrm{PtI}_{x} \mathrm{Cl}_{1-x}$ from $\mathrm{PtBr}_{x} \mathrm{Cl}_{1-x}$. Obviously the competition between two lengths, namely the PtI segment length and the PtI coherence length, will characterize the Raman behavior of $\mathrm{PtI}_{x} \mathrm{Cl}_{1-x}$.

To describe MX materials, we have developed the following extended two-band nearest-neighbor Peierls-Hubbard model Hamiltonian [3]:

$$
\begin{aligned}
H= & \sum_{i, \sigma}\left\{\left(-t_{0}+\alpha \Delta_{i}\right)\left(c_{i, \sigma}^{\dagger} c_{i+1, \sigma}+c_{i+1, \sigma}^{\dagger} c_{i, \sigma}\right)+\left(e_{i}+\beta_{i}\left(\Delta_{i}+\Delta_{i-1}\right)\right) n_{i, \sigma}\right\} \\
& +\sum_{i} U_{i} n_{i, \uparrow} n_{i, \downarrow}+\sum_{i}\left\{\frac{M_{i}}{2}{\dot{x_{i}}}^{2}+\frac{K_{M X}}{2} \Delta_{i}^{2}+\frac{\kappa_{i}}{2}\left(\Delta_{i}+\Delta_{i-1}\right)^{2}\right\}
\end{aligned}
$$

where $c_{i}^{\dagger}$ and $c_{i}$ are the electron creation and annihilation operators at site $i . t_{0}, \alpha$ and $\beta$ are, respectively, the hopping integral between adjacent $M$ and $X$ atoms, inter-site and on-site electronphonon couplings. $e_{i}$ is the on-site energy, which equals $+e_{0}$ for $\mathrm{Pt}$ ( $d$-orbital) and $-e_{0}$ for $\mathrm{X}$ ( $p$-orbital). $U_{i}$ is the on-site Coulomb interaction. The nearest neighbor $V$ term is neglected here but discussed elsewhere. $M_{i}$ is the mass of $\mathrm{M}$ or $\mathrm{X}$, and $K_{M X}$ is the spring constant between $\mathrm{M}$ and $\mathrm{X}, \kappa_{i}$ is the second-nearest-neighbor spring constant which we assume is none-zero only for $\kappa_{M M}$. $\Delta_{i}$ is the lattice distortion, defined as

$$
\Delta_{i}=x_{i}-x_{i-1}-a
$$

where $a$ is the average lattice constant. 
Table 1: Parameter sets for $\mathrm{PtCl}$ and PtI. The units are, $\mathrm{eV}$ for $t_{0}, e_{0}$, and $U, \mathrm{eV} / \AA$ for $\alpha$ and $\beta$, $\mathrm{eV} / \AA^{2}$ for $K$ and $\kappa_{M M}$.

\begin{tabular}{llllllllll}
\hline & $t_{0}$ & $e_{0}$ & $\alpha$ & $\beta_{M}$ & $\bar{\beta}_{X}$ & $\bar{U}_{M}$ & $U_{X}$ & $K_{M X}$ & $\bar{K}_{M M}$ \\
$\mathrm{PtCl}$ & 1.02 & 2.12 & 0.5 & 2.7 & -1.35 & 1.9 & 1.3 & 6.8 & 2.0 \\
$\mathrm{PtI}$ & 2.45 & 2.0 & 2.53 & 0.51 & -0.255 & 0.0 & 0.0 & 7.42 & 2.0 \\
\hline
\end{tabular}

There are two steps in our calculation: first, the mean-field (MFA) electronic spectrum is calculated by self-consistently solving Hamiltonian (1) with the following equation, which minimizes the total energy with respect to lattice distortion:

$$
K_{M X} \Delta_{i}+\kappa_{i}\left(\Delta_{i}+\Delta_{i+1}\right)+\kappa_{i-1}\left(\Delta_{i-1}+\Delta_{i}\right)=\sum_{\sigma}-\alpha_{i}\left\langle c_{i, \sigma}^{\dagger} c_{i+1, \sigma}+h . c .\right\rangle+\beta_{i} \rho_{i, \sigma}+\beta_{i+1} \rho_{i+1, \sigma}
$$

second, the optical spectrum and Raman cross section are calculated using a real-space random phase approximation (RPA) method [4].

The parameter sets for $\mathrm{PtCl}$ and $\mathrm{PtI}$ are shown in Table 1. They are obtained by fitting to the experimental stoichiometric ground state properties of pure PtX materials. The experimental data and theoretical results using parameter in Table 1 (shown in parenthesis), of the ground state properties for $\mathrm{PtCl}$ and $\mathrm{PtI}$ are respectively: the Peierls dimerization 0.38 and $0.12 \AA(0.384$ and 0.128 ); the Peierls energy gap 2.5 and $1.0 \mathrm{eV}$ (2.52 and 0.98); Raman frequency 305 and $113 \mathrm{~cm}^{-1}$ (306 and 115); infrared frequency 358 and $240 \mathrm{~cm}^{-1}$ (349 and 219).

We note that analytical expressions exist for the Fermi energy level (HOMO) and the lowest conduction band level (LUMO) of a pure MX material under our Hamiltonian (1), which in the case of $U_{M}=U_{X}=0$ and for a given Peierls dimerization $\Delta$, are given by

$$
\begin{gathered}
E^{L U M O}=\beta_{M} \Delta+\sqrt{2\left(t_{0}+\alpha \Delta\right)^{2}+\left(e_{0}+\beta_{M} \Delta\right)^{2}}, \\
E^{H O M O}=-\beta_{M}^{\prime} \Delta^{\prime}+\sqrt{2\left(t_{0}^{\prime}-\alpha^{\prime} \Delta^{\prime}\right)^{2}+\left(e_{0}^{\prime}-\beta_{M}^{\prime} \Delta^{\prime}\right)^{2}}+\left(e_{0}-e_{0}^{\prime}\right),
\end{gathered}
$$

respectively. The last term $\left(e_{0}-e_{0}^{\prime}\right)$ is added to keep the $\mathrm{Pt}$ on-site energy the same for two $\mathrm{PtX}$ materials. Comparing these two energy levels for two MX materials using Eqs. (4) and (5) can tell us whether or not we should expect intrinsic charge transfer effect when they are mixed. The parameters listed in Table 1 for the present $\mathrm{PtCl} / \mathrm{PtI}$ material satisfy:

$$
E_{P t C l}^{L U M O}>E_{P t I}^{H O M O} \text {, and } E_{P t I}^{L U M O}>E_{P t C l}^{\mathrm{HOMO}},
$$

implying that there will be no intrinsic charge transfer effect either from $\mathrm{PtCl}$ to $\mathrm{PtI}$ or vice versa. However, photo-induced charge transfer can still be observed in mixed $\mathrm{PtBr}_{x} \mathrm{Cl}_{1-x}$ [2] and probably in mixed $\mathrm{PtI}_{x} \mathrm{Cl}_{1-x}$ as well.

Table 2: PtI and accompanying PtCl Raman mode $\left(\mathrm{cm}^{-1}\right)$, and their resonance energy (eV) as function of PtI segment length.

\begin{tabular}{cccccccccc}
\hline & $\mathrm{PtI}$ & $\mathrm{Pt}^{N} \mathrm{I}_{2}$ & $\mathrm{Pt}^{I} \mathrm{I}_{2}$ & $\mathrm{PtI}_{3}$ & $\left(\mathrm{Pt}^{N} \mathrm{I}_{2}\right)_{2}$ & $\left(\mathrm{Pt}^{I} \mathrm{I}_{2}\right)_{2}$ & $\mathrm{PtI}_{5}$ & $\left(\mathrm{Pt}^{I V} \mathrm{I}_{2}\right)_{3}$ & $\left(\mathrm{Pt}^{I I} \mathrm{I}_{2}\right)_{7}$ \\
$\mathrm{PtI}$ & 156.5 & 172.1 & 166.2 & 176.3 & 153.7 & 143.0 & 160.8 & 143.6 & \\
$\mathrm{PtCl}$ & none & 302 & none & 302 & 300 & none & 301.5 & 295.9 & 125.6 \\
$E_{\nu} \dagger$ & 1.82 & 1.36 & 2.0 & 1.36 & 1.9 & 1.48 & 1.39 & 1.5 & \\
\hline
\end{tabular}




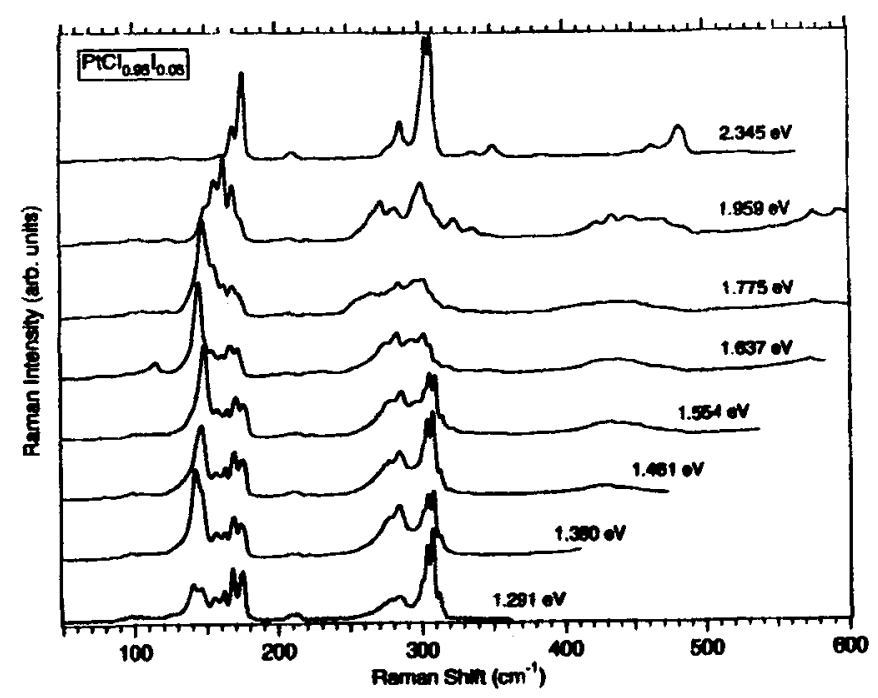

Figure 1: Experimental Raman intensity data on mixed $\mathrm{PtI}_{x} \mathrm{Cl}_{1-x}$ with $5 \% \mathrm{PtI}$ for several pumping energies.

We have systematically calculated the electronic band structure and optical Raman amplitude for $\mathrm{PtI}_{x} \mathrm{Cl}_{1-x}$ by varying the relative $\mathrm{PtI}$ and $\mathrm{PtCl}$ segment lengths. The calculated characteristic Raman modes for $\mathrm{PtI}_{x} \mathrm{Cl}_{1-x}$ are summarized in Table 2, while Fig. 1 shows a typical experimental measurement of Raman amplitude for a mixed $\mathrm{PtI}_{x} \mathrm{Cl}_{1-x}$ with $5 \% \mathrm{PtI}$. There are two regions in the Raman measurement, one for PtI in the range between $110 \mathrm{~cm}^{-1}$ to $176 \mathrm{~cm}^{-1}$, the other for $\mathrm{PtCl}$ between $280 \mathrm{~cm}^{-1}$ and $310 \mathrm{~cm}^{-1}$ (the features beyond $400 \mathrm{~cm}^{-1}$ are due to overtons). The PtI segment and $\mathrm{PtCl}$ frequencies shown in Table 2 are quite consistent with the experimental observations. The coexistence of different $\mathrm{PtI}$ and $\mathrm{PtCl}$ Raman modes in experimental data suggests that the measured sample are composed of randomly distributed different (short) PtI segments.

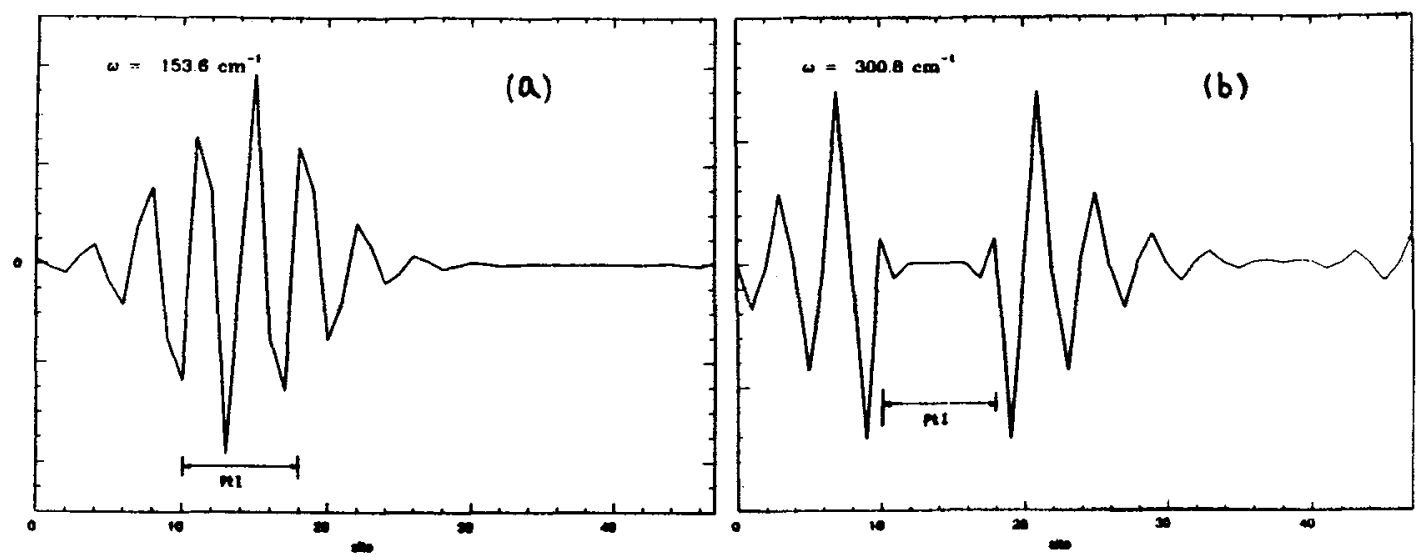

Figure 2: Calculated Raman characteristic phonon wave function for a $(\mathrm{PtI})_{4}(\mathrm{PtCl})_{20}$ chain: (a) $\mathrm{PtI}$ segment mode; and (b) accompanying $\mathrm{PtCl}$ mode. Unlabeled part is $\mathrm{PtCl}$.

From Table 2 and Fig. 1, we observe the following features:

First, the PtI Raman segment mode depends on its segment length. The PtI segment Raman 
frequency first increases with segment length until reaching $\mathrm{Pt}_{2} \mathrm{I}_{3}$, a characteristic length beyond which it starts to decrease. It approaches its pure chain mode of $113 \mathrm{~cm}^{-1}$ as the PtI segment becomes very long.

Second, there are $\mathrm{PtCl}$ modes (sometimes none) accompanying the PtI segment modes. They correspond to various lengths of $\mathrm{PtCl}$ segment, surrounded by two neighboring short $\mathrm{PtI}$ segments with the vibrational amplitude mostly located on the $\mathrm{PtCl}$ segment but also penetrating across the $\mathrm{PtI}$ segments. Fig. 1 (a) and (b) show a typical PtI segment and its accompanying $\mathrm{PtCl}$ phonon mode.

The segment dependence of $\mathrm{PtI}$ Raman mode is quite different from $\mathrm{PtBr}_{x} \mathrm{Cl}_{1-x}$, where the $\mathrm{PtBr}$ Raman segment mode monotonically decreases with $\mathrm{PtBr}$ segment length [1]. This different behavior originates in the different CDW strengths of $\mathrm{PtBr}$ and $\mathrm{PtI}$. $\mathrm{PtBr}$ is still a relatively localized CDW like $\mathrm{PtCl}$, with a typical polaronic width of 4 sites, while $\mathrm{PtI}$ is a very delocalized CDW (and thus easily deformed, see [5]) with a typical polaronic width of $\sim 30$ sites. Since the coherence length is so short in $\mathrm{PtCl}$, the $\mathrm{PtCl}$ segments on the two sides of a $\mathrm{PtI}$ segment act as hard boundaries for PtI. They also act as a strong perturbative force distorting the charge/lattice distribution in the weaker PtI segment. Therefore, a competition exists between the PtI segment length and its coherence length. Clearly, PtI can not fully relax if it is too short. The hard PtCl boundary dominates when the PtI segment length is below a characteristic length, while it has much less influence on $\mathrm{PtI}$ segment behavior above this length. In the case of $\mathrm{PtBr}_{x} \mathrm{Cl}_{1-x}$, however, the $\mathrm{PtBr}$ defect length is so short that even a short $\mathrm{PtBr}$ segment is almost fully relaxed. This is why we have different quantitative behavior for $\mathrm{PtBr}$ Raman mode in $\mathrm{PtBr}_{x} \mathrm{Cl}_{1-x}$ and $\mathrm{PtI}$ Raman mode in $\mathrm{PtI}_{x} \mathrm{Cl}_{1-x}$. The PtI segment, in turn, affects the $\mathrm{PtCl}$ Raman profile, reflected by the presence of $\mathrm{PtCl}$ mode, located near the interface of $\mathrm{PtI} / \mathrm{PtCl}$ on the $\mathrm{PtCl}$ side.
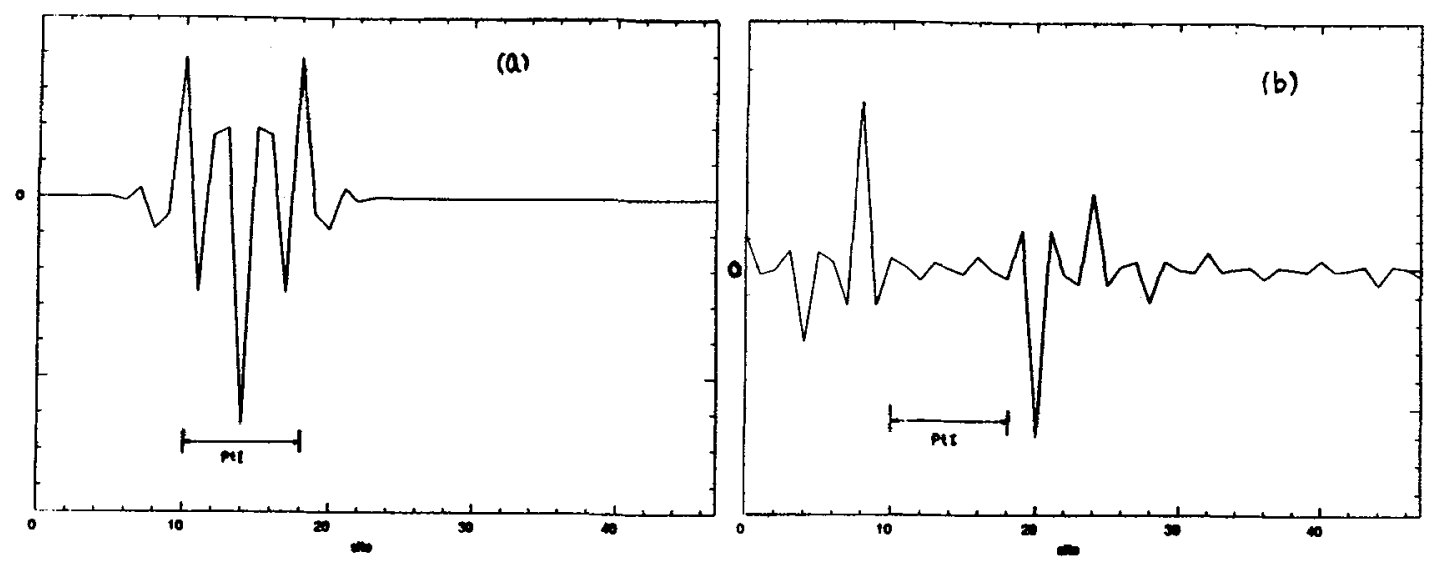

Figure 3: Calculated quasi-particle wave-functions for the same chain as in Fig. 2. (a) HOMO level with dominant $\mathrm{PtI}$ character; and (b) LUMO level with mostly $\mathrm{PtCl}$ character.

In order to identify any charge transfer effect, we need characterize two quasi-particle energy levels: HOMO and LUMO. Fig. 3 and show the single particle wave functions of these two levels for a mixed $\mathrm{PtI}_{x} \mathrm{Cl}_{1-x}$. We see that the HOMO (Fermi) level is strongly localized in the PtI segment, and the LUMO level has dominant amplitude on the $\mathrm{PtCl}$ side near the interface. We would therefore expect that when a particle-hole is created, the hole will be localized in the PtI segment, while the particle will be mostly on the $\mathrm{PtCl}$ segment near the interface. Motivated by this idea, we have calculated the electronic band structure and charge distribution for a triplet exciton (by creating a particle-hole pair with spin flip). Fig. 4 shows the charge distribution pattern of such a 
case. In this case, we found an extended hole bipolaron is formed in the $\left(\mathrm{Pt}^{I V} \mathrm{I}_{2}\right)_{2}$ segment (seen from the equal distribution of spin up and down densities) and two neighboring localized electron polarons formed on the $\mathrm{PtCl}$ segment near the interface. The corresponding Raman spectrum for a hole bi-polaron in PtI was also calculated. We found it has a characteristic frequency of $117 \mathrm{~cm}^{-1}$, in the right experimental range for the strong peak near $116 \mathrm{~cm}^{-1}$.

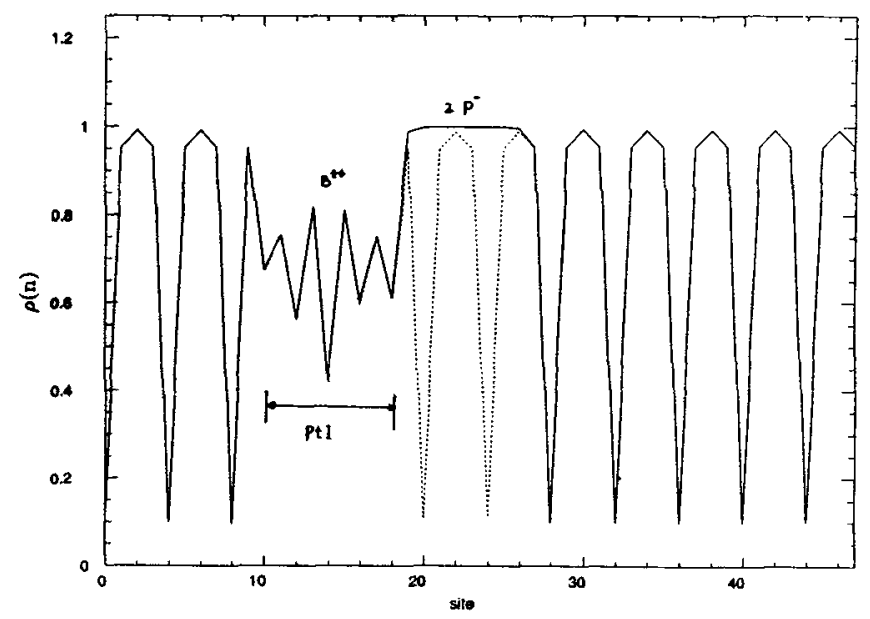

Figure 4: Calculated charge distribution of a triplet exciton for the same chain as Fig. 2. Solid line denotes spin up charge, and dotted line spin down. Both lines coincide in the PtI segment indicating a hole bipolaron, while two neighboring but separate (spin-up) electron polarons are formed in the $\mathrm{PtCl}$ segment.

In conclusion, in a combined experimental-theoretical efforts, we have studied systematically the segment length dependence of Raman frequencies in mixed halide $\mathrm{PtI}_{x} \mathrm{Cl}_{1-x}$. Unlike $\mathrm{PtBr}_{x} \mathrm{Cl}_{1-x}$, $\mathrm{PtI}_{x} \mathrm{Cl}_{1-x}$ shows a peak in the $\mathrm{PtI}$ segment Raman frequency at $\mathrm{Pt}_{2} \mathrm{I}_{3}$. Accompanying the $\mathrm{PtI}$ segment Raman modes are $\mathrm{PtCl}$ segment modes, which are enhanced correlatively with the $\mathrm{PtCl}$ segment modes. The coherence length of MX, characterized, e.g. by its polaronic defect width, plays an important role in determining the electronic and optical properties of mixed halide 'MXX' materials. Numerical calculation on electronic band structure suggests a possible photo-induced charge transfer effect.

We thank B. Swanson and S. Love for providing us with their experimental Raman measurement and useful discussions. This work is supported by Department of Energy of the U.S. government.

\section{REFERENCES}

[1] Huang X. Z., Saxena A., Bishop A. R., Worl L. A., Love S. P., Swanson B. I., Solid State Comm. 84 (1992) 957.

[2] Worl L. A. et al., J. Phys.: Condens. Matter, 4, (1992) 10237.

[3] Gammel J. T., Saxena A., Batistić I., Bishop A. R., Phillpot S. R., Phys. Rev. B. 45 (1992) 6408; Weber-Milbrodt S. M., et al., ibid. (1992) 6438.

[4] Batistić I., Bishop A. R., Phys. Rev. B. 45 (1992) 5282.

[5] X. Z. Huang et al., Synthetic Metal 56 (1993) 3438; X. Z. Huang, A. Saxena, A. R. Bishop, ibid 56 (1993) 3449. 